\title{
Correction: Ryan, J., et al. Application of the Hyperspectral Imager for the Coastal Ocean to Phytoplankton Ecology Studies in Monterey Bay, CA, USA. Remote Sens. 2014, 6, 1007-1025
}

\author{
Marcos J. Montes ${ }^{1, *}$, John P. Ryan ${ }^{2}$, Curtiss O. Davis ${ }^{3}$, Nicholas B. Tufillaro ${ }^{3}$ \\ and Raphael M. Kudela ${ }^{4}$
}

1 Remote Sensing Division, Naval Research Laboratory, 4555 Overlook Avenue SW, Washington, DC 20375, USA

2 Monterey Bay Aquarium Research Institute, 7700 Sandholdt Road, Moss Landing, CA 95039, USA; E-Mail: ryjo@mbari.org

3 College of Earth, Ocean and Atmospheric Sciences, Oregon State University, 104 CEOAS Admin. Bldg., Corvallis, OR 97331, USA;

E-Mails: cdavis@coas.oregonstate.edu (C.O.D.); nbt@ coas.oregonstate.edu (N.B.T.)

4 Ocean Science Department, University of California-Santa Cruz, 1156 High Street, Santa Cruz, CA 95064, USA; E-Mail: kudela@ucsc.edu

* Author to whom correspondence should be addressed; E-Mail: marcos.montes@nrl.navy.mil; Tel.: +1-202-767-7308; Fax: +1-202-404-8894.

Academic Editors: Xiaofeng Li and Prasad S. Thenkabail

Received: 28 September 2015 / Accepted: 8 October 2015 / Published: 12 October 2015

Studies of phytoplankton ecology in Monterey Bay, CA, USA, using the Hyperspectral Imager for the Coastal Ocean (HICO) and other satellite remote sensing and in-situ observations, were presented in [1]. Errors were made in Section 2.1 and Figure 9 regarding application of the ATREM [2] and Tafkaa 6s [3] atmospheric correction algorithms to HICO data. Here we present a correction of those errors and confirm that these errors did not affect the ecological interpretations presented in the original paper.

The second paragraph of Section 2.1 incorrectly described how ATREM was run. The 4th sentence of the 2nd paragraph in this section incorrectly read, "A Rayleigh scattering correction was applied based on solar and viewing geometry to obtain the Rayleigh-corrected intermediate reflectance spectrum". This is corrected to read, "A continental aerosol correction with a visibility of $300 \mathrm{~km}$ (resulting in an aerosol optical depth at $550 \mathrm{~nm}$ of 0.0853) was applied based on solar and viewing geometry to obtain an intermediate reflectance spectrum". Sentences 8 and 9 of the same paragraph 
should then read, "In addition to this modified computation, ATREM also computed and corrected for atmospheric gas absorption. For a direct comparison to the ATREM results, Tafkaa 6s was similarly configured". In the original paper, Tafkaa 6s was configured for a Rayleigh scattering correction (no aerosol) applied based on solar and viewing geometry to obtain the Rayleigh-corrected intermediate reflectance spectrum. This was not a proper comparison, and here we present Tafkaa 6s results with conditions identical to the ATREM run (described above), with these results post-processed in an identical manner as the ATREM results to remove the effects of sun glint, thin clouds, fog, and the spectrally independent portion of aerosol effects.

Figure 9 in the original paper had results from ATREM with a continental aerosol with an optical depth of 0.0853 (at $550 \mathrm{~nm}$ ) and post-processing specified in Section 2.1, compared to a Tafkaa 6s calculation run with pure Rayleigh (no aerosol) calculation and no post-processing, which provided a very different result. The corrected Figure 9 shows results from identical continental aerosol with an optical depth of 0.0853 at $550 \mathrm{~nm}$ for both Tafkaa 6s and ATREM, and identical post-processing. When calculations are performed correctly using ATREM and Tafkaa 6s, the results are virtually identical.

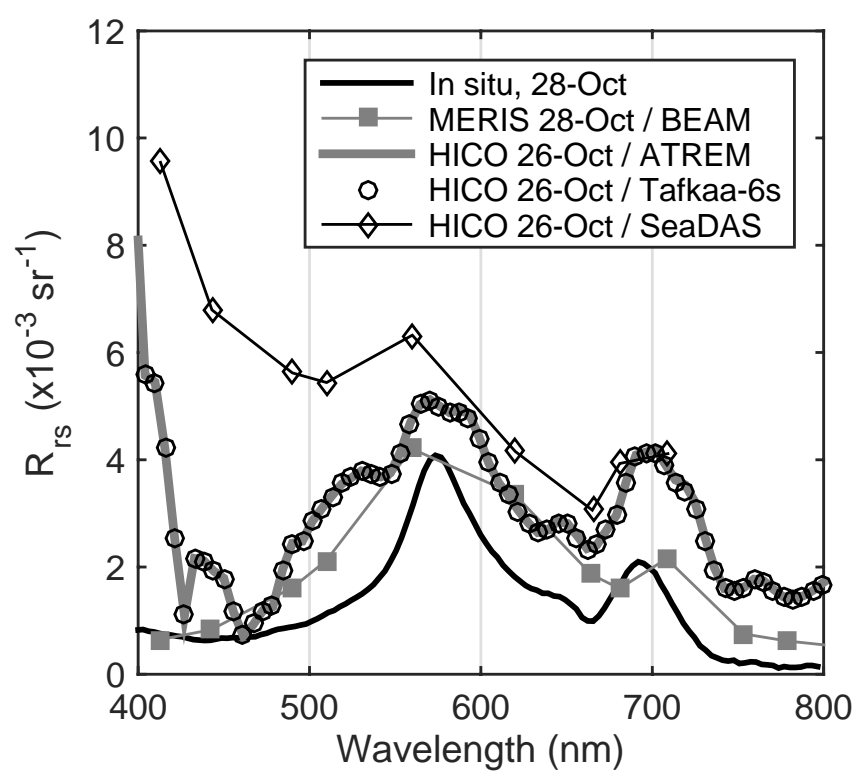

Figure 9. (Revised). Fall 2011 study: Ground truth optical measurements acquired along the periphery of a red tide patch on 28 October 2011 (location shown in Figure 8b). The in-situ $\mathrm{R}_{\mathrm{rs}}$ spectrum was acquired $59 \mathrm{~min}$ after the MERIS image. HICO spectra are $3 \times 3$ pixel means from the location shown in Figure 7c (zoom panel). The Tafkaa 6 s and ATREM results are nearly identical, and the lines are completely overlaid at the resolution of this figure.

All HICO images were reprocessed correctly using Tafkaa $6 \mathrm{~s}$, and the results were examined to assess any significant changes. This confirmed that all ecological interpretations based on HICO observations were robust as presented in the original article [1].

Reference 17 in the original article [1] should be corrected to be identical to reference [3], below. 


\section{Acknowledgments}

Bo-Cai Gao provided the ATREM output files that were used for the results of [1].

\section{Author Contributions}

M.J.M. analyzed the ATREM results and determined the actual optical depth that was used in [1]. He ran Tafkaa 6s for both the pure Rayleigh and continental at 0.0853 optical depth cases. M.J.M. drafted this manuscript and coordinated reexamination of HICO results with the authors J.P.R., C.O.D., N.B.T., and R.M.K. All the co-authors contributed to writing this correction.

\section{Conflicts of Interest}

The authors declare no conflict of interest.

\section{References}

1. Ryan, J.P.; Davis, C.O.; Tufillaro, N.B.; Kudela, R.M.; Gao, B.-C. Application of the hyperspectral imager for the coastal ocean to phytoplankton ecology studies in Monterey Bay, CA, USA. Remote Sens. 2014, 6, 1007-1025.

2. Gao, B.-C.; Davis, C.O. Development of a line-by-line-based atmosphere removal algorithm for airborne and spaceborne imaging spectrometers. Proc. SPIE 1997, doi:10.1117/12.283822.

3. Montes, M.J.; Gao, B.-C.; Davis, C.O. NRL Atmospheric Correction Algorithms for Oceans: Tafkaa User's Guide; NRL Report NRL/MR/7230-04-8760; NRL: Washington, DC, USA, 2004. Available online: http://www.dtic.mil/cgi-bin/GetTRDoc?AD=ADA422068 (accessed on 17 July 2015).

(C) 2015 by the authors; licensee MDPI, Basel, Switzerland. This article is an open access article distributed under the terms and conditions of the Creative Commons Attribution license (http://creativecommons.org/licenses/by/4.0/). 